\title{
A ESCOLA NA CONSTRUÇÃO DO PENSAMENTO PEDAGÓGICO: TEORIAS PEDAGÓGICAS CONSERVADORA E PROGRESSISTA
}

\author{
ESCUELA EN LA CONSTRUCCÍON DEL PENSAMIENTO PEDAGÓGICO: TEORÍAS \\ PEDAGÓGICAS CONSERVADORAS Y PROGRESSIVAS
}

\begin{abstract}
THE SCHOOL IN THE CONSTRUCTION OF THE PEDAGOGICAL THINKING: CONSERVATIVE AND PROGRESSIVE PEDAGOGICAL THEORIES
\end{abstract}

\author{
Hélcia Macedo de Carvalho Diniz e SILVA ${ }^{1}$ \\ Tânia Rodrigues PALHANO ${ }^{2}$
}

RESUMO: A relevância de teorias pedagógicas é discussão central no âmbito deste texto, que tem por objetivo geral analisar as teorias pedagógicas, conservadora e progressista, à luz do pensamento de Saviani (1999), que faz críticas à Bourdieu e Passeron (1970) em sua teoria da escola como reprodução, e Althusser (1980), por sua leitura estruturalista da educação como ideologia. Estas, configuram-se como pressupostos de aprendizagem que incidiram na prática escolar brasileira. Justifica-se a presente investigação filosófica por favorecer a discussão sobre os fundamentos essenciais no âmbito da Filosofia da Educação. O desenvolvimento tem por base materiais bibliográficos, websites e artigos científicos, Inter alia, com o uso de ferramentas metodológicas, de natureza qualitativa, método dedutivo e caráter interpretativista. O quadro teórico-metodológico de Mikhail Bakhtin (1981) sobre o já-dito e as vozes dos textos consiste em metodologia desta análise do discurso. Como resultados, demonstra-se a teoria pedagógica de Saviani (1999) que, de certa forma, está presente na prática escolar brasileira. Para tanto, a pergunta que se estabelece é a seguinte: como as teorias conservadora e progressista coexistem ao lado da teoria histórico-crítica no fazer docente no âmbito da escola?

PALAVRAS-CHAVE: Teoria conservadora. Teoria progressista. Teoria histórico-crítica. Análise do discurso segundo Bakhtin. Educação.

RESUMEN: La relevancia de las teorías pedagógicas es una discusión central de este texto, que tiene como objetivo general analizar las teorías pedagógicas, conservadoras y progresistas a la luz del pensamiento de Saviani (1999), que critica a Bourdieu y Passeron (1970) en su teoría escolar como una reproducción y Althusser (1980) por su lectura estructuralista de educación como ideología. Estos son supuestos de aprendizaje que se centran en la práctica escolar brasileña. Esta investigación filosófica se justifica por los fundamentos esenciales de la Filosofia de la Educación. El desarrollo se basa en materiales bibliográficos, sitios web y artículos científicos, entre otras cosas, con la utilización de instrumentos metodológicos, de

\footnotetext{
${ }^{1}$ Universidade de Brasília (UNB), Brasília - DF - Brasil. Professora Substituta do Departamento de Teorias e Fundamentos (FE/TEF) e Professora Titular do Curso de Direito (UNIPÊ) - João Pessoa. Doutorado em Educação (UFPB), Doutorado em Linguística (UFPB) e Doutorado em Filosofia (PUC-Rio). ORCID: https://orcid.org/00000002-4719-0863. E-mail: helciamacedo@gmail.com

${ }^{2}$ Universidade Federal da Paraíba (UFPB), João Pessoa - PB - Brasil. Professora Associada de Filosofia da Educação do Centro de Educação e Docente do Programa de Pós-graduação em Educação. Pós-Doutorado em Educação (UNICAMP). ORCID: https://orcid.org/0000-0003-3573-6889. E-mail: taniarpalhano@gmail.com
}

RIAEE - Revista Ibero-Americana de Estudos em Educação, Araraquara, v. 16, n. 3, p. 1860-1877, jul./set. 2021. e-ISSN: 1982-5587 
carácter cualitativo, método deductivo y carácter interpretativo. El marco teóricometodológico de Mikhail Bakhtin (1981) sobre lo ya dicho y las voces de los textos consiste en una metodología de investigación para tratar el análisis del discurso. Como resultados, se demuestra la teoría pedagógica de Saviani (1999) presente en la práctica escolar brasileña. Para ello, la pregunta es: ¿cómo las teorías pedagógicas conservadoras y progresistas están junto de la pedagogía histórico-crítica para los profesores en la escuela?

PALABRAS CLAVE: Teoría conservadora. Teoría progresista. Teoría histórico-crítica. Análisis del discurso según Bakhtin. Educación.

ABSTRACT: The relevance of pedagogical theories is the main discussion in this text's ambit, which has as it's general objective to analyze the theories of pedagogy, either conservative and progressive, lightened by Saviani's (1999) thinking, which criticized Bourdieu and Passeron (1970) in its school theory as reproduction and Althusser (1980) by its structuralist reading of education as an ideology. These configure themselves as learning assumptions that focused in the brazilian scholar practice. It becomes necessary to stress that the concept of pedagogical theories brought, expressly, a comprehension of the education and its school practice. In this context, the present philosophical investigation is justified, which figures itself inside the Philosophy of Education's ambit as a fundament. The development is based on bibliographical materials, websites and scientific articles, Inter alia, through methodological tools that concentrate on a qualitative approach, of deductive method and interpretive character. The theorical-methodological piece of Mikhail Bakhtin (1981) about the already-mentioned and the voices of the texts constitute itself to a necessary methodology for the development in the discourse's analysis of the authors mentioned above. Results displayed, the pedagogical theory of Savani (1999) is demonstrated to be present in the brazilian school practice. Therefore, the question that is established is the following: how do conservative and progressive pedagogical theories coexist, and are these theories historical critics developed by the teachers in the school setting?

KEYWORDS: Conservative theory. Progressive theory. Historical-critical theory. Discourse analysis according to Bakhtin. Education.

\section{Introdução}

Com o intuito de analisar teorias pedagógicas para o processo de ensino-aprendizagem, uma vez que ensinar e aprender são intercambiáveis, considera-se estas teorias, aqui, como pressupostos para o fazer escolar. Os objetivos específicos consistem em discorrer sobre escola e cultura no âmbito de teorias pedagógicas conservadoras, examinar a relação trabalho-escola no contexto de teorias pedagógicas progressistas e investigar, no contexto escolar, o processo de educação e realidade histórica.

A Pesquisa se justifica por se inserir no âmbito da Filosofia da Educação voltada para a escola, tem por objetivo geral analisar as teorias pedagógicas, conservadora e progressista, à luz do pensamento de Saviani, e desenvolve-se a partir dos seguintes objetivos específicos: 
discorrer sobre escola e cultura no âmbito de teorias pedagógicas conservadoras, examinar a relação trabalho e escola por meio de teorias pedagógicas progressistas e investigar a escola em relação à educação e realidade histórico-crítica. Faz-se mister salientar que o conceito de teorias pedagógicas trouxe, expressamente, uma compreensão da educação e de sua prática escolar.

O desenho metodológico do artigo reside em uma revisão de literatura em bases de dados, websites e artigos científicos, com uma abordagem qualitativa, método dedutivo e natureza interpretativista. Tem como meio a metodologia desenvolvida no quadro teóricometodológico de Mikhail Bakhtin (1981) sobre o já-dito e as vozes dos textos, em se tratando de análise de discurso.

No quadro teórico-metodológico, a partir da obra Problemas da poética de Dostoiévski (PPD), de Bakhtin (1981), encontra-se o conceito de dialogismo para realização da análise do discurso, mostrando que os discursos não se constroem nem se reduzem a uma só voz, que há já-ditos, palavra outra e as ressignificações. São vozes subjacentes e constitutivas no discurso constitutivo histórico, social e ideológico.

Ademais, já-ditos consistem em vozes do discurso alheio em nosso argumento. Isso ocorre no uso da linguagem sobre algum tema, assim como ao falar sobre teorias pedagógicas em contextos dialógicos e, por isso, circunscrevem a possibilidade de diferenciação no uso da palavra que forma o corpo da ideia; nesse entendimento, a análise do discurso que se segue está pautada na teoria-metodológica bakhtiniana. Para tanto, a pergunta que se estabelece é a seguinte: como as teorias conservadora e progressista coexistem ao lado da teoria históricocrítica no fazer docente no âmbito da escola?

Os argumentos ancoram-se no pensamento de Saviani (1999), cujas críticas às teorias progressista e conservadora demonstram que estas reduzem a função da escola a uma mera reprodução do poder dominante. Saviani (1999) critica o pensamento dos franceses Bourdieu e Passeron (1970), no livro intitulado A reprodução, afirmando ser uma teoria do sistema de ensino enquanto violência simbólica, que caracteriza a escola como reprodutora da sociedade e esquece o caráter dinâmico do fazer educacional.

Saviani (1999) critica, ainda, a teoria de Althusser (1980) sobre a Ideologia e aparelhos ideológicos do Estado, uma leitura estruturalista do marxismo que encara a educação como ideológica com fundamento que não apresenta uma articulação sólida, limitando-se de modo indireto ao conceito de lutas de classes e do predomínio da classe dominadora no sistema capitalista, cuja referência é, necessariamente, weberiana, com o campo teórico da Sociologia da Educação como teoria geral da sociedade. 
As ideias dos autores estudados nesta pesquisa foram desenvolvidas com vistas ao processo educacional escolar. Percebendo que as teorias observadas careciam de fundamentos, Saviani (1999) articula a teoria histórico-crítica com vistas às questões da educação brasileira, cuja contribuição considerada original propõe uma visão teórica para além dos pensadores que o antecederam.

Esta pesquisa, portanto, apresenta três seções: Inicialmente, o pensamento de Bourdieu e Passeron (1992) sobre a reprodução, expondo o conceito de que a escola reproduz a sociedade da qual faz parte. Em seguida, o pensamento de Althusser: a ideologia e aparelhos ideológicos do Estado, na obra que trata a escola como espaço de formação para o trabalho; e, por último, a teoria histórico-crítica de Saviani, com uma proposta que está para além do pensamento conservador e progressista, propondo uma escola com trabalhos fundamentados na teoria histórico-crítica. Esta é a estrutura e a subdivisão deste trabalho, cujo desenvolvimento resenha cada pensamento, de modo a preservar a ideia central de cada pensador; este é um estudo pontual e ampliado das realidades educacionais brasileiras.

Esta pesquisa faz uma apresentação suficiente e delimitada de teorias pedagógicas para mostrar que o trabalho do filósofo e pedagogo brasileiro Saviani (1982) está para além dos pensadores apresentados quando o assunto é a educação escolar brasileira, fato percebido nos livros publicados contendo a pedagogia da Teoria Histórico-crítica.

\section{Bourdieu e Passeron sobre a Pedagogia Racional}

Esta seção mostra a análise de Bourdieu e Passeron (1992) sobre a escola, na qual os autores consideram a instituição escolar como um espaço de reprodução do campo social. Entendem que é por meio da escola que crianças e adolescentes adquirem determinados conhecimentos, os quais variam de acordo com a região.

O assunto abordado em sala de aula é considerado pela sociedade em geral tema valioso, para ser trabalhado dentro do arcabouço teórico educacional consolidado por uma tradição pedagógica. Bourdieu e Passeron (1992) questionaram a razão de as crianças, geralmente, sentirem dificuldade para a apropriação dos conhecimentos impostos pelo padrão escolar que estão pré-determinados pelos educadores. Os autores argumentaram que no contexto educacional a maioria do conteúdo eleito para o ensino é extraído de um cânone ou de uma seleção feita por determinado grupo de profissionais da educação.

Ao observar que são os profissionais da educação que selecionam os temas a partir do que está presente na sociedade, Bourdieu e Passeron (1992) defenderam a ideia de que isso 
forma o capital cultural, social e econômico. Há efeitos e relações sociais construídas para formar a legitimidade que não é dada pela posse da pessoa, e sim favorece o processo de ensinoaprendizagem, por exemplo, com conhecimentos valorizando a cultura já reconhecida, aquilo que é simplesmente dado pelas pessoas que fazem parte tanto da sociedade como da escola. Esta, por sua vez, reproduz o conhecimento a partir da cultura da sociedade: o que é considerado mais valioso e o que corresponde à cultura legítima e ao capital cultural.

Determinadas pessoas da sociedade têm condições de adquirir, por exemplo, as expressões refinadas construindo conhecimentos prévios que advêm de sua condição social e financeira. Nesses casos, o capital cultural é constituído pela leitura, visitas aos museus, jogos, pinturas e telas, fontes que não estão amplamente difundidas na sociedade, não havendo espaço para o que ainda não foi explorado.

Assim, uma pessoa que fica ausente do contato das informações preestabelecidas por determinado grupo social sente-se excluída do processo de conhecimento, principalmente por não ter tido acesso às informações canonizadas como sendo as que se deve aprender. Geralmente, as escolas acabam reproduzindo essa cultura e considerando conhecimentos essenciais e naturais, o que na realidade não são: “Cada família transmite a seus filhos, mais por vias indiretas que diretas, um certo capital cultural [...] que contribui para definir, entre outras coisas, as atitudes em face ao capital cultural e da instituição escolar" (BOURDIEU; PASSERON, 1992, p. 42).

Partindo do fato de que cada família tem a sua realidade e visão de mundo, percebe-se que o mesmo ocorre com o docente, cuja formação acaba enformando o seu conhecimento e sua visão é distinta da do discente, principalmente por conta da experiência adquirida durante o processo formativo, como os fatores relacionados às atividades e o acesso à informação. Ademais, cabe ao docente o controle da sala e do tempo da aula, a chamada nominal para registrar a presença/ausência do discente e as atribuições peculiares do fazer docente. $\mathrm{O}$ volume de trabalho em sala de aula dificulta a percepção do docente em relação às diferenças entre os discentes e às realidades que há em uma só turma, sem falar do que distingue discentes de docentes, além de haver diferenças sociais entre eles. De modo amplo, os docentes acabam nivelando uma turma e não compreendem que o capital cultural de cada discente varia de acordo com cada realidade (SAVIANI; PASSERON, 1992).

Quando o discente chega à escola desprovido de capital cultural, fica uma lacuna enorme que dificulta a aquisição do conhecimento. Então, se alguém não o ajuda ou ele mesmo não se esforça para aprender, torna-se notório que o seu desempenho é inferior àquele que tem uma base cultural. No contexto escolar é preciso preparar o ambiente para oportunizar aprendizado 
a todos os envolvidos no processo. "Oferecer a todos uma tecnologia de trabalho intelectual e inculcar-lhes métodos racionais de trabalho será uma maneira de contribuir para reduzir as desigualdades ligadas à herança cultural”, defendem Bourdieu e Passeron (1992, p. 71).

A explicação dos autores mostra que a lacuna amplia as chances de fracasso do discente em seu processo de ensino-aprendizagem. Consta no livro A Reprodução: elementos para uma teoria do ensino, de Bourdieu e Passeron (1992), que ocorre na escola o seguinte: o discente repete o conteúdo e não se apropria dele porque é levado à memorização e à reprodução. $\mathrm{O}$ fato de se conhecer as leis da reprodução abre alguma chance de minimizar a ação reprodutora da instituição escolar. Se tem uma escola que promete identificar potenciais, no sentido de apontar quem é mais inteligente, mais esforçado ou mais motivado para seguir em frente, esta trabalha para averiguar quem tem mais capital cultural, quem aprende com mais eficiência aquele conteúdo pré-selecionado.

$\mathrm{Na}$ avaliação, há o discente que se sai bem no campo da linguagem, aquele no campo da matemática e outro nas ciências. Na realidade, quando a pessoa se destaca em determinado campo, é porque há uma vivência cultural mais profunda do assunto para além dos muros da escola, ou seja, tem um capital cultural que foi construído não na escola, mas fora dela.

O discente mediano, que não preocupa de modo geral, é aquele que responde apenas ao que se pede nas avaliações. Nesse caso, o discente apresenta apenas o que foi apresentado pela escola, pelo docente, porque the falta minimamente o capital cultural. Esse aprendizado mediano acompanha a formação educacional por longo período, caso o discente não se esforce para suprir as lacunas do seu aprendizado.

Há aqueles que não dispõem de capital cultural, mas tem o investimento familiar e o contato com a escola. Este, geralmente, não se destaca e se esforça para chegar a responder ao que a escola pede. Está muito longe do que pede e, mais ainda, daquele conhecimento que vai além da reprodução escolar. Esta é a realidade da grande maioria, porque são esses discentes que não atingem as habilidades/capacidades e competências exigidas pela educação formal.

Toda escola que trabalha identificando as etapas dos seus discentes foge do seu papel social, isto é, se distancia do seu papel social no processo de ensino-aprendizagem. $\mathrm{Na}$ realidade, as avaliações, os índices e as formas de mensurar em que lugar está o discente são tipos do denominado método de meritocracia, que acaba mostrando uma disparidade entre as pessoas, dos que tem relação natural com as linguagens em relação àqueles que, por qualquer razão, não puderam ter contato com o ensino do uso da língua e seus desdobramentos. "Para que sejam favorecidos os mais favorecidos e desfavorecidos os mais desfavorecidos, é necessário e suficiente que a escola ignore [...] as desigualdades culturais entre as crianças das 
diferentes classes sociais" (BOURDIEU; PASSERON, 1992, p. 71). É preciso que cada docente se faça a seguinte pergunta: como docente estou ajudando a ratificar a origem social de cada discente? O que estou fazendo na escola, uma vez que não há uma permissão para que o discente se aprimore e possa crescer, ao sair deste ambiente de formação?

De modo objetivo, a contribuição do docente é relevante no trabalho de ensinoaprendizagem, deslocando a origem social de cada discente, o fazer escolar e o crescimento intelectual. Isso ocorre diante das limitações estruturais de cada discente, que acaba por abandonar o ambiente escolar por se sentir impedido de aprimorar conhecimentos, se sentido incapaz de aprender.

A escola neutraliza o discente, que ao passar pela escola sente que o processo apenas ratifica aquilo que ele já conhecia/sabia antes dos seus estudos escolares. Isto justifica o efeito social, o discente que se dá bem na escola, se dá bem na vida, uma máxima que acaba identificando as pessoas e faz a reprodução da desigualdade social, transforma as classificações sociais como algo justo porque vem dos méritos individuais das pessoas. Bourdieu e Passeron (1992, p. 3) afirmam que: "não é exagerado dizer que o ensino é, em parte, um fator de inércia".

Ao realizar a sua função de docente tem-se por objetivo transformar o discente com relação ao conhecimento e às mudanças sociais. Não obstante, o efeito que o docente acaba fazendo não é compatível com o seu objetivo, e acaba contribuindo na manutenção das relações de dominação social. Para Bourdieu e Passeron (1992, p. 3):

Os docentes não conseguem mudar essa realidade, porque o docente passou com sucesso pela trajetória escolar, por mais acidentada que possa ter sido a sua trajetória como discente, ele conseguiu se adequar a lógica e caba considerando natural e adequado o modo como o sistema funciona.

Submerso nesse ambiente de naturalização do sistema educacional, o docente não consegue enxergar outra realidade, provavelmente por conta de sua longa trajetória escolar, do modo como funcionou o seu aprendizado e da relação com o capital cultural. Tudo isso fica internalizado na pessoa e acaba neutralizando o seu senso crítico sobre o processo de ensinoaprendizagem.

Como faz parte da maneira como cada pessoa assimila o conhecimento, a reprodução social acaba perpetuando a visão de que a escola é justa e identifica o mérito do discente. $\mathrm{Na}$ medida que a avaliação da escola pretende ser neutra, o seu trabalho torna-se, para muitos, inquestionável, até porque a família e a sociedade ratificam esse entendimento.

Segundo Bourdieu e Passeron (1992), o sucesso escolar está associado com a disposição do ser humano para o conhecimento. Para alguns, por exemplo, ir à escola é algo obrigatório e 
natural, uma crença que se ajusta à imagem que a própria escola imprime, cujo objetivo é o de formar e preparar para o mundo. É, até mesmo, à imagem que os pais passam para seus filhos. $\mathrm{Na}$ maioria das vezes, nem é esta visão da escola que se sobressai, porque alguns discentes vivenciam a exclusão social.

Essa denúncia dos autores mostra como os mecanismos sociais são sutis e difíceis de serem percebidos. A forma do funcionamento escolar constrói a percepção de mundo. A trajetória do docente, por exemplo, define a sua percepção em relação à escola. Os mecanismos perversos de exclusão social ficam invisíveis, uma vez que a pessoa não consegue pensar este ambiente de outra forma. O funcionamento é visto de uma única forma, a que foi apresentada desde sempre, desde o início, quando a instituição escolar foi criada, uma característica que está em sua constituição.

Uma primeira leitura desse texto, com a visão menos aprofundada, pode dar a impressão de que não há jeito de resolver o problema em relação ao fato de docentes serem colaboradores que ratificam o sistema de desigualdade social. Na escola, por exemplo, a plasticidade da linguagem permite ao sujeito falante a atitude de assumir a forma do que é adequado para o contexto. Evidenciando a questão do uso da linguagem como uma prática que contém as diferenças regionais e diversidade nos diferentes contextos sociais, a questão é a seguinte: quem se sente mais legítimo, o que fala de modo formal ou aquele que usa a linguagem informal? Para tal pergunta é necessário considerar que o uso da linguagem é fator relevante em se tratando do contexto educacional. Há casos em que, muitas vezes, o uso da linguagem torna-se fonte de exclusão social, em outras situações é justamente o uso da linguagem que favorece a inclusão.

Para Bourdieu e Passeron (1992), a linguagem está no interior dos espaços de processos educacionais. Assim, há agressão por parte da escola em relação ao discente que não consegue aprender a língua materna. Por exemplo, a pessoa que frequenta escola e não fala corretamente a língua padrão é um alvo fácil para a discriminação, ou seja, para sentir-se inferior diante dos demais.

Outra questão é imperativa para Bourdieu e Passeron (1992), a saber, como o docente pode proporcionar um repertório de operações mentais, de vocabulário para pessoas que não dispõem de um conhecimento prévio? Os autores sugerem que uma "pedagogia realmente racional, isto é, fundada sobre uma sociologia das desigualdades culturais, contribuiria para diminuir as desigualdades diante da escola e da cultura" (BOURDIEU; PASSERON, 1992, p. 9). 
Bourdieu e Champagne (1997) debruçaram-se nesse argumento e redigiram como resultado de suas pesquisas o artigo "Os Excluidos do Interior", que trata a realidade da escola e dos cursos de ensino superior: por exemplo, há faculdades mais conceituadas no quesito avaliação que exigem severos processos de seleção e, por conseguinte, mais conhecimento cultural. Nestas, a maioria dos discentes possuem maior capital cultural. Diferentemente do que acontece em faculdades com cursos menos reconhecidos, aqueles que oferecem mais vagas que candidatos, nestas a realidade apresentada pelos discentes revela o pouco capital cultural, seja ao ingressarem no curso superior seja após a conclusão do curso.

Outra realidade é o fato de docentes, por exemplo, afirmarem que há discentes que não sabem ler nem escrever. Estes são os mais excluídos no interior porque está na escola, matriculado, frequentando e não conseguem aprender o básico, ler e escrever. Os autores afirmam que a escola age como se fosse um funil, exclui de forma continuada, exerce violência simbólica ao ratificar a exclusão da sociedade em seu interior porque o comentário do docente ratifica a dificuldade do discente, ao invés de tentar ajudar e mudar a situação.

A violência simbólica é arbitrária em relação àquilo que está sendo valorizado em determinado contexto social, por isso violenta. Não apenas isso, aqueles que são portadores de outros conhecimentos, diferentes dos que são ditados pela sociedade, também se veem diminuídos. "A violência simbólica nunca se exerce sem uma forma de cumplicidade extorquida daqueles que a sofrem" (BOURDIEU; PASSERON, 1992).

A aula, por exemplo, com determinada pintura, expressão de arte visual popular na sociedade, geralmente é ministrada porque aquele artefato é reconhecido como sendo melhor. Portanto, importante e merecedora de exposições e de ocupar aulas inteiras, expressão artística considerada superior a algumas que jamais seriam eleitas para ser objeto de estudo.

Esse acontecimento não é dado pelo fato de que existe alguma coisa de essencialmente melhor nessa obra escolhida, e sim porque o acordo social entre as pessoas que lidam com aula, arte e valores define o que é relevante naquele contexto histórico, social e cultural. Na medida em que determinado contexto com determinadas pessoas escolhe valorizar isso e desvalorizar aquilo, toda herança que se traz junta-se a esses valores.

Uma compressão que está interiorizada nas pessoas, isto é, a natureza do ser humano, é cultural, seus valores, formas de compreender o mundo, organizar o ambiente e de se mover no mundo. Há expressões individuais numa compreensão comum a todos ao enfrentar os desafios da vida, porque o dia a dia é imprevisível, principalmente em se tratando do espaço de sala de aula. Por exemplo, o docente prepara a aula $\mathrm{X}$ e pretende seguir a sua sequência didáticopedagógica. Contudo, há o fator surpresa do contexto de sala de aula que pode apresentar 
encaminhamentos outros nos pensamentos e compreensões de alguns discentes, que não hesitam em colocar uma questão sobre o tema $\mathrm{Y}$, geralmente distinta do assunto que está sendo abordado.

Nessa situação o docente tem de reagir ao que é inesperado na sala de aula. Diante disso, aquele que está na posição de ministrante da aula tem reações que não são aleatórias. De fato, a ele não é dado o tempo mínimo para refletir a situação. Sem tempo para pensar sobre a questão, faz uso da razão prática. Isso é da ordem do habitus. "O corpo está no mundo social, e o mundo social está no corpo" (BOURDIEU; PASSERON, 1992, p. 71). Muitas vezes, esse acontecimento gera tensões e abala o relacionamento docente-discente: com isso está criado o ambiente de violência simbólica.

No contexto escolar o docente não tem tempo de parar e pensar, além do assunto é preciso dar conta de variáveis como: conteúdo, controle da turma e tempo, por exemplo. Além disso, há situações em que não dá tempo para pensar e que exigem uma providência instantânea. O juízo que o docente constrói sobre os discentes pode ser percebido, explicam os autores, nos adjetivos que são usados para classificar os trabalhos escritos. Em alguma medida a avaliação está colada à figura do discente. A avaliação pelos docentes está profundamente contaminada por aquilo que eles percebem da origem social do discente, um tipo de percepção intuitiva daquilo transmitido por ele mesmo, que remete ao seu próprio capital social.

Os efeitos possíveis das denúncias de Bourdieu e Passeron (1992) enfatizaram fatos que incidem na escola. Especificamente, quando se percebe a realidade e se constata como o social se constrói e se articula com eventos reais. Para os autores é possível e há condições de se pensar estratégias de ação, "o que o mundo social fez o mundo social pode desfazer" (BOURDIEU; PASSERON, 1992, p. 71). Nesses termos, a educação, portanto, foi considerada como uma reprodução da sociedade no interior escolar. Não obstante, há outras teorias que se preocuparam com o processo formal do ensino-aprendizagem, como se pode ver adiante na perspectiva de Althusser (1980), que passamos a apresentar.

\section{Althusser: escola, aparelhos ideológicos e Estado}

Neste desenvolvimento a pesquisa apontou o pensamento de Althusser sobre a educação como um autor marxista, que entende a estrutura da sociedade como sendo infraestrutura e superestrutura, dividida em classes. $\mathrm{O}$ dono do meio de produção e aquele que serve ao meio de produção, ambos se utilizam do meio. Assim, o tema da educação é uma reprodução nas 
condições de produção, "toda formação social deve reproduzir as condições da sua produção, as forças produtivas e as relações de produção existente" (ALTHUSSER, 1980, p. 20).

A qualificação do sujeito para o trabalho exige que seja introduzida a escola, como principal meio de qualificação do trabalhador. O aperfeiçoamento do sujeito é feito pelo "sistema escolar capitalistas e outras instâncias e instituições" (ALTHUSSER, 1980, p. 20). A escola oferece dois conhecimentos: 1. Saber técnico para o manuseio de equipamentos, conforme a função a ser desempenhada (operário, engenheiro, digitador, docente em meio digital, entre outros); 2. As "regras dos bons costumes, isto é, o comportamento que todo agente da divisão de trabalho deve observar, segundo o lugar que está destinado a ocupar" (ALTHUSSER, 1980, p. 21).

Althusser (1980, p. 20) critica o sistema escolar ao afirmar que a força de trabalho é qualificada e reproduzida "nos diferentes 'postos' e 'empregos', através do sistema escolar e outras instituições”. Nesse contexto, o autor critica o sistema escolar ao constatar que é lá que o sujeito aprende a ler, contar, escrever e outros saberes práticos, assim como regras de bom comportamento, costumes que devem ser cumpridos pelo sujeito no seu lugar na divisão de trabalho. Isso porque ao aprender esses conteúdos o sujeito acaba sendo moldado ao sistema.

O autor chama a atenção, ainda, para o papel da Religião que se institucionaliza para ensinar aos futuros operários doutrinas. No caso do Brasil, reportamos o ensino de Educação Moral e Cívica (EMC) e Organização Social e Política Brasileira (OSPB), como meio de trabalhar o civismo. Ambas as disciplinas com o objetivo de ensinar ao sujeito a obedecer de modo passivo. Althusser (1980, p. 22) afirma que "a reprodução da força de trabalho exige não só uma reprodução da qualificação desta, mas, ao mesmo tempo, uma reprodução da submissão desta às regras da ordem estabelecida", como a moral do bem e do mal.

Para o autor, a reprodução da força de trabalho tem como pressuposto e condição a eficácia, qualificação e imposição da ideologia. Isso favorece o sujeito em relação à condição e qualidade de vida (emprego, plano de saúde, educação, segurança) e obediência (cumprimentos) dos deveres do Estado. Este é o primeiro alvo de análise do filósofo francês. Althusser (1980, p. 31) afirma:

A tradição marxista é peremptória. O Estado é explicitamente concebido a partir do Manifesto e do 18 Brumário (e em todos os textos clássicos ulteriores, sobretudo de Marx sobre a Comuna de Paris e de Lenine sobre o Estado e a Revolução como aparelho repressivo. O Estado é uma 'máquina' de repressão que permite às classes dominantes (no século XIX à classe burguesa e à 'classe' dos proletários de terras) assegurar a sua dominação sobre a classe operária para a submeter ao processo de extorsão da mais-valia (quer dizer, à exploração capitalista). 
O aparelho de Estado, que é o próprio Estado, define-se na luta de classes com a função fundamental do poder que exerce sobre aqueles que possuem apenas a sua força de trabalho e luta com todas as forças, por meio da política, que gira em torno da tomada do poder de Estado. Tomar o poder de Estado significa querer controlar o aparelho de Estado, modificando ou não o seu funcionamento.

A linguagem usada pelo teórico para definir cada aparelho ideológico é a seguinte: Sistema Religioso (sistema de diferentes igrejas); Escolar (compreende o sistema de diferentes escolas, públicas e privadas); Familiar (famílias): Jurídico (normas, leis, regras); Político (compreende o sistema com os diferentes partidos); Informação (imprensa, rádio, televisão, internet, redes sociais). O Religioso pertence ao domínio privado, dispersa-se com mais rapidez, por exemplo, ou funcionando pela ideologia: "Em 1931, à época do decreto relativo ao ensino religioso, não se externara, ainda, o conflito entre católicos e os escolanovistas" (SAVIANI, 2013, p. 197).

É único o tipo de aparelho (repressivo) de Estado. Pertence ao domínio público, concentra-se funcionando em maior grau pela violência e em menor grau pela ideologia, por exemplo, a violência e a coerção ideológicas praticadas pelo aparelho policial. Para Althusser (1980), a escola funciona por meio da ideologia, seja pública ou privada, sendo que dispõe de uma gama de métodos de exclusão, castigo, segregação e seleção para formar o discente, geralmente considerado um rebelde, um diamante bruto que precisa ser lapidado.

Assim, um aparelho ideológico de Estado possui uma contradição interna de luta de classes mais aparentes, uma vez que há interesses distintos entre as classes sociais. As relações de produção estão presentes na reprodução por meio da hegemonia da classe dominante, ação intrínseca tanto no aparelho repressivo de Estado como nos aparelhos ideológicos de Estado.

As propostas pedagógicas conservadora e progressista, apresentadas anteriormente, foram criticadas por Saviani (1999), a primeira cujo foco é a escola e cultura, e a segunda apontando para a relação escola e trabalho. Tais teorias se limitam, sucessivamente, à reprodução do conhecimento e ratificação da cultura eleita por um grupo de pessoas e a escola como aparelho ideológico do Estado. A seguir apresentamos o pensamento de Saviani (1999) sobre a pedagogia histórico-crítica, que supera os entendimentos expostos até o momento.

\section{Saviani e a Teoria Histórico-Crítica}

Na Teoria Histórico-crítica, Saviani (1999) desenvolveu três teses, a saber, a primeira é a tese filosófico-histórica: do caráter revolucionário da pedagogia tradicional e do caráter 
reacionário da pedagogia nova; a segunda é a tese pedagógico-metodológica: do caráter científico do método tradicional e do caráter pseudocientífico dos métodos novos; e a terceira é a tese político-educacional: de como quando mais se falou em democracia nas escolas, menos ela foi democrática e quando menos se falou em democracia, mais ela foi democrática, quer dizer que a escola tradicional funcionava como instrumento de acesso à democracia, enquanto na escola nova se falava em democracia a todo momento, mas isso acabava não acontecendo.

O núcleo básico dessa teoria pedagógica encontra-se na distinção das posições liberais de inspiração marxista, que prometiam uma educação crítica, ativa, transformadora para formar a consciência crítica; contudo, segundo Saviani (1999), estas promessas nunca foram cumpridas.

Diante disso, Saviani (1999) propõe, no campo das teorias pedagógicas, uma teoria que se adequa à realidade educacional brasileira. Na obra Escola e Democracia o autor apresenta a teoria da curvatura da vara. Nesta defende a ideia de que é necessário buscar o equilíbrio, e para atingi-lo deve-se produzir uma tensão para que a vara pendida para o lado oposto encontre o justo meio.

É este sentido de negação frontal das teses correntes que se traduz metaforicamente na expressão 'teoria da curvatura da vara'. Com efeito, assim como para endireitar uma vara que se encontra torta não basta coloca-la na posição correta, é necessário curvá-la do lado oposto, assim, também, no embate ideológico, não basta enunciar a concepção correta para que os desvios sejam corrigidos; é necessário abalar as certezas, desautorizar o senso comum (SAVIANI, 2006, p. 60).

Quando a vara está curvada para o lado errado, é necessário curvá-la para o lado oposto, a fim de retomar a posição e ficar no ponto certo. Esta teoria tem as seguintes etapas: $1^{\circ}$ ) docente e discente, agentes sociais; $2^{\circ}$ ) problematização, detectar e refletir sobre os problemas; $3^{\circ}$ ) instrumentalização, ferramentas necessárias para a ação; $4^{\circ}$ ) cartas, incorporação dos subsídios ou ferramentas; $5^{\circ}$ ) prática social, uma ação orgânica, ou práxis, como desenvolvido a seguir.

Tal como está posto, pode-se entender, segundo a análise de Saviani (1999, p. 46), que "as pedagogias novas são portadoras de todas as virtudes, enquanto a pedagogia tradicional é portadora de todos os defeitos e de nenhuma virtude". Se é assim a vara está curvada para a escola nova, e os defensores desse pensamento acreditam que as suas propostas estão conseguindo corrigir esse desvio de curvatura.

A escola tradicional foi criada para redimir a sociedade e converter pessoas, quando ela era revolucionária, buscando fazer com que os súditos se tornassem cidadãos. Quando se tornou conservadora, esqueceu esse ideal, passou a justificar a desigualdade, de modo reacionário. 
Uma posição do pensamento revolucionário não está nem no campo da teoria tradicional nem da escola nova, mas numa teoria que supere a ambas, incorporando seus avanços e superando os seus limites.

Em seguida, para além da teoria da curvatura da vara, considerando que as teses anteriores são mais bem definidas quando vistas como antíteses por refutar premissas como as defendidas pela Escola Nova, porque acreditam na escola como redenção da educação. $\mathrm{O}$ educar reafirma que as pedagogias não-críticas não historicizam as dinâmicas processuais do ensino-aprendizagem, por isso não conseguem alcançar entendimento mais amplo acerca de influências contextuais: política, econômica e social.

A proposta, aqui, vai em direção a tarefas pedagógicas que levam em conta os demais setores da sociedade no processo de transformação social, a fim de abrir espaço para uma construção paulatina de uma sociedade mais justa. A pedagogia crítica compreende o papel da educação inserido na dinâmica social e não na transformação da realidade, simplesmente. Não obstante, o processo educacional histórico-crítico pode cumprir um papel fundamental nesse processo, haja vista a relação dialética da educação com a sociedade, que "sendo determinada, exerce determinação no processo de transformação social" (SAVIANI, 1999, p. 71).

Saviani (1999) elaborou a Teoria Histórico-crítica e demonstrou historicamente e de modo crítico que tanto a pedagogia tradicional como a pedagogia nova podem ser consideradas ingênuas e idealistas, por acreditarem que seria possível modificar a sociedade por meio da educação. Segundo Saviani (2006, p. 37), a curvatura da vara,

Conforme Althusser (1997, p. 136-137), foi enunciada por Lênin ao ser criticado por assumir posições extremistas e radicais. Lênin responde o seguinte: 'quando a vara está torta ela fica curva de um lado e se você quiser endireita-la, não basta coloca-la na posição correta. É preciso curvá-la para o lado oposto.

Assumir posturas extremistas e radicais proporciona que sejam feitos os ajustes essenciais no processo de ensino-aprendizagem. Com uma teoria crítica não reprodutivista, cujo primeiro capítulo versa sobre educação e o problema da marginalidade, Saviani (1982) elabora uma análise das teorias não críticas. Aponta para uma necessidade de uma teoria que fosse além desses limites. No segundo capítulo, história e democracia ou a teoria da curvatura da vara, abre-se a polêmica com a Escola Nova. No terceiro, história e democracia para além da teoria da curvatura da vara, delineia o que foi denominado em 1984 de Pedagogia Histórico-crítica.

A teoria de Saviani (1999) foi construída com base na concepção dialética materialista a partir do modo como Marx trabalhou o seu método voltado para a economia, no livro 
Contribuição para a crítica da Economia Política (MARX, 2008), as anotações do método de economia política. Neste, Marx põe como cerne da questão o conhecimento que se desenvolve, que é parte das impressões imediatas, parte de um todo empírico (primeiro momento), mas um todo caótico. Uma visão confusa que se tem da realidade e, a partir da análise desse todo, vaise para o momento analítico (segundo momento), da abstração, para identificar quais são os elementos que caracterizam esse todo. A partir deste ponto, é preciso fazer o caminho inverso e reconstruir esse todo, agora compreendido esse todo como uma síntese de múltiplas determinações: nesse momento se chega ao concreto.

Assim, a teoria de Saviani (1999) parte do empírico e chega ao concreto pela mediação do abstrato. Em outras palavras, parte da síncrese e pela mediação da análise chega-se à síntese. O discente inicia-se no conhecimento com uma visão sincrética (confusa). O papel da escola é fazer o discente ultrapassar a visão sincrética (percepção imediata) e alcançar a visão sintética (o concreto é a unidade na diversidade).

O concreto é o ponto de chegada. O ponto de partida é o empírico (o homem não conhece diretamente a base que é a percepção imediata do concreto, que se vê apenas parte e pode ser experimentada. Com a análise, passa-se a compreender essa realidade, o ato abstrato de compreender permite que se chegue ao concreto). O materialismo histórico é centrado na história, o homem é produto da história e a educação tem o papel de permitir que as novas gerações se apropriem dos conhecimentos acumulados ao longo da vida.

\section{Considerações finais}

A exposição sobre as teorias pedagógicas conservadora e progressista, apresentadas nas teorias de Bourdieu e Passeron (1992) e Althusser (1980), forneceram indícios conceituais para responder à questão de pesquisa quanto a coexistência e o desenvolvimento de tais teorias no âmbito escolar.

Inicialmente, a pedagogia racional de Bourdieu e Passeron (1992) mostrou a evidência de que a escola consiste na instituição que pratica a reprodução social, na qual crianças adquirem conhecimentos convencionados pelo capital cultural, social e econômico. Sendo a reprodução da arte e da matéria, por exemplo, veiculada por ser reconhecida por determinada camada social e intelectual. Isso exerce sobre o discente uma violência simbólica.

Em seguida, apresentando Althusser (1980), destacou-se a sua linguagem conceitual dos Aparelhos Ideológicos de Estado (AIE), forte no âmbito privado, com a ideologia marcando o funcionamento escolar, bem como as instituições como a religião, a família e o político, por 
exemplo. Não obstante, este conceito atinge as escolas públicas por conta de o domínio ideológico dispensar força sobre os escolares. No caso do Aparelho de Estado (AE), que é único e tem uma ação violenta por conta do domínio público sobre os cidadãos, ocorre a coerção, por exemplo, praticada pelo aparelho policial.

As concepções dos franceses, Bourdieu e Passeron (1992), assim como a de Althusser são a conservadora e a progressista, respectivamente. Isso porque limitam-se à reprodução do conhecimento e à ideologia do aparelho ideológico do Estado, tomando a educação não como ato de transformação, mas como consolidação do poder sobre o sujeito, que permanece passivo no processo de estudar, porque só repete o que lhe é ensinado. Este é um processo de formação de sujeitos que serve apenas para consolidar o poder, sem postura crítica e criativa.

As reflexões e discussões acerca das teorias pedagógicas, pelo pensamento de Saviani (1999), apresentaram uma análise que promoveu o alcance dos objetivos propostos, ao discorrer sobre escola e cultura no âmbito de teorias pedagógicas conservadoras, examinar a relação trabalho escolar por meio de teorias pedagógicas progressistas e investigar a escola em relação à educação e realidade histórica.

Saviani (1999), por sua vez, imprime uma teoria que critica o caráter revolucionário da pedagogia tradicional e o caráter reacionário da pedagogia nova. O critério para uma educação crítica visa a transformação do sujeito. A isso, soma-se outra crítica, a do caráter científico do método tradicional e do caráter pseudocientífico dos métodos novos. Além dessas críticas, Saviani (1982) afirmou que quando se falava em democracia, esta não se fazia presente na escola. Antes disso, faziam-se processos escolares sem se preocupar com o processo democrático, justamente neste período a escola realizava vivências democráticas.

Diante desta análise, Saviani (1982) propôs a teoria histórico-crítica, construída na base dialético-materialista, que parte do empírico e chega ao concreto pela mediação do abstrato. Primeiro, o discente tem uma visão sincrética do objeto de estudo, e por meio da escola, chega a uma visão sintética, ao sintetizar os conhecimentos de modo concreto, reconhecendo a diversidade que há entre tantas matérias. Deste ponto, enfim, o discente aprofunda seus conhecimentos e chega por meio da empiria ao ponto de chegada, o concreto.

Os estudos estão centrados na história, no produto dela e na possibilidade de sua ampliação: a educação permite às novas gerações o reconhecimento de riquezas acumuladas, e o aluno aprende, seguindo em frente de modo crítico, contribuindo para um mundo melhor e mais justo.

É importante destacar neste estudo a possibilidade de desdobramentos como o fato de que na realidade há, no âmbito escolar, a coexistência destas três teorias: casos em que o docente 
assimila e desenvolve o campo teórico da educação perpetuando a Pedagogia Conservadora; situações em que alguns docentes transpõem os limites do conservadorismo e aplicam a Pedagogia Progressista; por último, há docentes adeptos da Pedagogia histórico-crítica. Para outras pesquisas, é possível que se façam estudos de casos, recortando determinados contextos para saber a predominância atual das teorias pedagógicas que persistem no fazer educacional.

\section{REFERÊNCIAS}

ALTHUSSER, L. Ideologia e aparelhos ideológicos de estado. Lisboa: Presença/Martins Fontes, 1980.

BAKHTIN, M. M. Problema da poética de Dostoiévski. Rio de Janeiro: ForenseUniversitária, 1981.

BOURDIEU, P.; PASSERON, J-C. A reprodução: elementos para uma teoria do sistema de ensino. Rio de Janeiro: Livraria Francisco Alves, 1992.

BOURDIEU, P.; CHAMPAGNE, P. Os excluídos do interior. In: BOURDIEU, P. (org.) A miséria do mundo. Rio de Janeiro: Vozes, 1997.

MARX, K. Contribuição à crítica da economia política. São Paulo: Expressão popular, 2008.

SAVIANI, D. Escola e Democracia: teorias da educação, curvatura da vare, onze teses sobre educação e política. São Paulo: Cortez/Autores Associados, 1999.

SAVIANI, D. História das ideias pedagógicas no Brasil. Campinas, SP: Autores Associadas, 2013.

SAVIANI, D. Aberturas para a história da educação. Campinas, SP: Autores Associadas, 2013

\section{Como referenciar este artigo}

SILVA, H. M. C. D; PALHANO, T. R. Escola na construção do pensamento pedagógico: teorias pedagógicas conservadora e progressista. Revista Ibero-Americana de Estudos em Educação, Araraquara, v. 16, n. 3, p. 1860-1877, jul./set. 2021. e-ISSN: 1982-5587. DOI: https://doi.org/10.21723/riaee.v16i3.13750 
Revisões requeridas em: 13/01/2021

Aprovado em: 10/02/2021

Publicado em: 01/07/2021 